\title{
A taxonomic reassessment of Piramys auffenbergi, a neglected turtle from the late Miocene of Piram Island, Gujarat, India
}

\author{
Gabriel S Ferreira ${ }^{\text {Corresp., }}{ }^{1,2}{ }^{\text {, Saswati Bandyopadhyay }{ }^{3} \text {, Walter G Joyce }}{ }^{\text {Corresp. } 4}$ \\ ${ }^{1}$ Faculdade de Filosofia, Ciências e Letras de Ribeirão Preto, Universidade de São Paulo, Ribeirão Preto, Brazil \\ 2 Fachbereich Geowissenschaften, Eberhard-Karls-Universität Tübingen, Germany \\ 3 Geological Studies Unit, Indian Statistical Institute, Kolkata, India \\ 4 Departement für Geowissenschaften, University of Friberg, Freiburg, Switzerland \\ Corresponding Authors: Gabriel S Ferreira, Walter G Joyce \\ Email address: gsferreira@usp.br, walter.joyce@unifr.ch
}

Background. Piramys auffenbergi was described as an emydine turtle based on a well-preserved skull retrieved from late Miocene deposits exposed on Piram Island, India. The description and figures provided in the original publication are vague and do not support assignment to Emydinae. This taxon has mostly been ignored by subsequent authors.

Material \& Methods. We reexamine the holotype specimen and provide an extensive description and diagnosis for Piramys auffenbergi and included this taxon in a global character-taxon matrix for Pleurodira.

Results. The presence of a processus trochlearis pterygoidei conclusively shows pleurodiran affinities for Piramys auffenbergi. Inclusion of this taxon in a phylogenetic analysis retrieves it within Stereogenyini and as sister to the Asian taxa Shweboemys pilgrimi and Brontochelys gaffneyi.

Discussion. Our reexamination of the holotype of Piramys auffenbergi confidently rejects the original assessment of this taxon as an emydine testudinoid and conclusively shows affinities with the pleurodiran clade Stereogenyini instead. Even though most taxa from this lineage are thought to be coastal turtles, all Asian stereogenyines were collected from continental deposits, suggesting a more diverse paleoecology for the group. 


\section{A taxonomic reassessment of Piramys auffenbergi, a neglected turtle}

\section{2 from the late Miocene of Piram Island, Gujarat, India}

4 Gabriel S. Ferreira ${ }^{1,2}$, Saswati Bandyopadhyay ${ }^{3}$, Walter G. Joyce ${ }^{4}$

6 'Faculdade de Filosofia, Ciências e Letras de Ribeirão Preto, Universidade de São Paulo,

7 Ribeirão Preto, Brazil

$8 \quad{ }^{2}$ Fachbereich Geowissenschaften, Eberhard-Karls-Universität Tübingen, Tübingen, Germany

$9{ }^{3}$ Geological Studies Unit, Indian Statistical Institute, Kolkata, India

${ }^{4}$ Departement für Geowissenschaften, Universität Freiburg, Freiburg, Switzerland

*Walter G. Joyce, walter.joyce@unifr.ch, walter.g.joyce@gmail.com

ABSTRACT

Background. Piramys auffenbergi was described as an emydine turtle based on a well-preserved skull retrieved from late Miocene deposits exposed on Piram Island, India. The description and figures provided in the original publication are vague and do not support assignment to Emydinae. This taxon has mostly been ignored by subsequent authors.

Material \& Methods. We reexamine the holotype specimen and provide an extensive description and diagnosis for Piramys auffenbergi and included this taxon in a global charactertaxon matrix for Pleurodira.

Results. The presence of a processus trochlearis pterygoidei conclusively shows pleurodiran affinities for Piramys auffenbergi. Inclusion of this taxon in a phylogenetic analysis retrieves it 
24 within Stereogenyini and as sister to the Asian taxa Shweboemys pilgrimi and Brontochelys 25 gaffneyi.

26 Discussion. Our reexamination of the holotype of Piramys auffenbergi confidently rejects the

27 original assessment of this taxon as an emydine testudinoid and conclusively shows affinities with the pleurodiran clade Stereogenyini instead. Even though most taxa from this lineage are

thought to be coastal turtles, all Asian stereogenyines were collected from continental deposits, suggesting a more diverse paleoecology for the group.

\section{INTRODUCTION}

Piramys auffenbergi was described by Prasad (1974) based on a single skull (GSI 18133) retrieved from Neogene sediments exposed on the small island of Piram, Gujarat State, India (Fig. 1). Prasad (1974) identified the taxon as an emydine, but the diagnosis and the description are general and do not reveal any emydine affinities. Today, only cryptodiran cheloniids, geoemydids (formerly part of Emydidae), testudinids, and trionychids occur in India (TTWG, 2017), but stereogenyine pleurodires inhabited the area as recently as the Plio/Pleistocene (Gaffney et al., 2011).

Here we provide an extensive description and diagnosis of Piramys auffenbergi based on a reexamination of the holotype specimen. Phylogenetic analysis concludes that this taxon is a representative of Stereogenyini, a clade that includes other South Asian forms, namely the Plio/Pleistocene Shweboemys pilgrimi Swinton, 1939 from Myanmar, and the late Oligocene Brontochelys gaffneyi (Wood, 1970) from Pakistan. We also provide an updated account of the paleoecology and biogeography of the group, concluding that, although they were most likely 
46 adapted (or at least highly tolerant) to salty waters, stereogenyines were still restricted

47 geographically and not as widespread as modern sea turtles.

48 Institutional abbreviations. - GSI, Geological Survey of India, Kolkata, India.

49

50

51

52

53

54

55

56

57

SYSTEMATIC PALEONTOLOGY

$$
\text { PLEURODIRA Cope, } 1865
$$

PELOMEDUSOIDES Broin, 1988

PODOCNEMIDIDAE Cope, 1868

STEREOGENYINI Gaffney et al., 2011

STEREOGENYITA Gaffney et al., 2011

Piramys auffenbergi Prasad, 1974

Holotype.- GSI 18133, a partial skull (Prasad, 1974, figs. 2-4, pl. 3.1; Figure 2).

Type locality and horizon.- Piram Island (Fig. 1), Gulf of Khambhat (formerly Gulf of Cambay), Gujarat, India; conglomerate beds, middle Siwaliks (Prasad, 1974), Dhok Pathan age, late Miocene (Nanda, Sehgal \& Chauhan, 2017).

Referred material.- No specimens have been referred to date.

Diagnosis.-Piramys auffenbergi can be diagnosed as a representative of Pleurodira by the presence of the processus trochlearis pterygoidei and of Pelomedusoides by the absence of nasal bones. Piramys auffenbergi can be further diagnosed as a representative of Stereogenyini by the small entrance to the antrum postoticum, the condylus mandibularis projecting ventrally from the cavum tympani, and the posteriorly broad skull, and as a member of Stereogenyita closer to Shweboemys pilgrimi and Stereogenys cromeri by a median notch in the upper jaw. Piramys auffenbergi is distinguished from the other members of Stereogenyini by the following 
combination of characters: a pinched snout (not present in Latentemys plowdeni Gaffney et al., 2011, Bairdemys venezuelensis [Wood \& Díaz de Gamero, 1971], and B. sanchezi Gaffney et al., 2008), a deep interorbital groove on the prefrontal and frontal (otherwise present in Cordichelys antiqua [Andrews, 1903]), foramen nervi trigemini located above the level of the sulcus palatinopterygoideus (in contrast to the more ventrally displaced foramen nervi trigemini in Shweboemys pilgrimi and Brontochelys gaffneyi), the lower temporal emargination rising above the ventral level of the orbit (shallower in C. antiqua and unknown for other Stereogenyita), and the foramen stapedio-temporale placed anteriorly (autapomorphic character).

\section{DESCRIPTION}

Preservation.-The skull was likely buried intact but suffered much weathering damage more recently. The bone is nevertheless of good quality and sutures are well preserved. The palate and ventral aspects of the basicranium are still obscured by matrix, but the dermatocranium and the dorsal parts of the basicranium are exposed (Fig. 2). The margins of the external nares and the median portions of the labial margins are damaged, but the remaining margins likely approximate their original outlines. The temporal roofing, by contrast, is massively eroded and the extent of the upper temporal emarginations can therefore not be assessed anymore. Much of the postorbitals, parietals, quadratojugals, squamosals, and the supraoccipital are missing. Faint scute sulci are apparent on the postorbitals and parietals (Fig. 2A).

88 Prefrontal. - The prefrontals are relatively small, paired elements that form the anterodorsal aspects of the orbit and the anterior third of the narrow interorbital space. The anterior margins are damaged, but the prefrontals likely formed the dorsal roof of the external nares, as nasals were absent. The prefrontals contact the frontals posteriorly along a straight, transverse suture, 
92 the maxillae ventrally along a straight, horizontal suture, and one another along a straight,

93 median suture. The descending branch of the prefrontal contacts the frontal posteriorly and the

94 maxilla ventrally, but potential, more-distal contacts with the vomer and palatine are obscured by

95 matrix (Fig. 2C). The prefrontals jointly form a deep, median grove on the dorsal skull surface

96 (Fig. 2A).

97 Frontal. - The frontals are the only bones that are undamaged. The dorsal plate of the frontals

98 forms the posterior two thirds of the interorbital space and posterodorsal margins of the anterolaterally facing orbits. The frontals contact the prefrontals anteriorly along a straight, transverse suture, the postorbitals laterally along parasagittal sutures of uneven length, the parietals posteriorly along straight, transverse sutures, and one another along a straight, median suture. Within the orbits, the frontals contact the prefrontals anteriorly and the postorbitals laterally. The median groove formed by the prefrontals continues posteriorly onto the frontals (Fig. 2A), but fades to oblivion towards the posterior margins of these elements.

Parietal.-Symmetric damage to the dorsal plate of the parietal creates the illusion that the parietals are relatively small elements that define the margins of well-developed upper temporal emarginations, but all margins show signs of damage and the extent of this emargination cannot be assessed with any confidence. It is therefore only clear that the dorsal plates of the parietals contact the frontals anteriorly along straight, transverse sutures and the postorbitals along oblique, anterolateral sutures. Together with the postorbitals, the parietals form a pair of sulci that converge towards the posterior and that likely trace the outline of a large internarial scute 112 (scute ii of Ferreira et al., 2015) that covered the prefrontals, frontals, and the medial portions of

113 the postorbitals and parietals. The descending process of the parietals contacts the pterygoid anterior to the foramen nervi trigemini, forms the dorsal margin of this foramen, and contacts the 
115 prootic and supraoccipital posterior to it (Fig. 2A). The foramen nervi trigemini is located above

116 the level of the sulcus palatinopterygoideus and is well separated from the foramen stapedio-

117 temporale by the prootic (Fig. 2C). More anterior contacts, if present, are obscured by matrix.

118 Postorbital. - The posterior margins of the postorbitals show signs of damage and it is

119 therefore not possible to assess if they originally contributed to the upper temporal

120 emarginations, although the thickness of their damaged margins makes this implausible.

121 However, as the intact posterior margins converge, it is unlikely that they were significantly

122 larger than preserved. The dorsal plates of the postorbitals at least contact the frontals medially, 123 the parietals posteromedially, the jugals ventrally, and the quadratojugals posterolaterally. The

124 descending process of the postorbital forms much of the posterior wall of the orbit, but its distal

125 contacts are obscured by matrix. We are not able to discern a dorsal pocket within the upper

126 limits of the posterior wall of the orbit.

127 Jugal. - The jugals are relatively large elements that form the posteroventral aspects of the 128 orbit. Although the posteroventral aspects are damaged on both sides, enough is preserved to 129 indicate that a well-developed lower temporal emargination is developed that rises to the level of 130 the lower third of the orbit and that is anterodorsally framed by the jugals (Fig. 2B). The jugals 131 contact the postorbitals dorsally along horizontal sutures, the quadratojugal posteriorly along a 132 transverse suture, and the maxillae anteroventrally along a slightly oblique suture. The jugals 133 contact the maxilla anteriorly and the postorbitals laterally on the surface of the skull, but matrix 134 obscures possible contacts within the orbit.

135 Quadratojugal.- Only a fragment of the quadratojugal remains on the right side of the skull 136 (Fig. 2B). It is therefore unclear if the quadratojugal contributes to the upper or lower temporal 137 emarginations, although a contribution to the lower temporal emargination appears highly likely. 
138 Only a short, anteromedial contact is preserved with the postorbital, an elongate anterior contact

139 with the jugal, and remnants of the posterior contact of the quadrate anterior to the cavum

140 tympani.

141 Squamosal. - A fragment of the right squamosal is available at the back of the skull (Fig. 2A).

142 This fragment contacts the quadrate anterolaterally and the opisthotic anteromedially within the

143 upper temporal fossa. A likely contribution of the squamosal to the region posterior to the cavum

144 tympani cannot be discerned from that of the quadrate. However, the massive nature of the

145 damaged quadrates suggests that the squamosal did not contribute to the antrum postoticum.

146 Premaxilla.-The anterior tip of the skull is damaged, but the median, cleft like notch appears

147 to be genuine, as much of the left labial margin is intact (Fig. 2D). We are unable to discern the

148 contacts, or even the presence, of premaxillae.

149 Maxilla.- The maxillae can only be observed in anterior and lateral views, as the palate is

150 hidden by matrix. On the skull surface, the high maxillae contact the jugals below the orbit along

151 transverse sutures and the prefrontals dorsally along horizontal suture. These contacts can

152 partially be traced within the orbits, but matrix obscures their full extent. It is unclear if an

153 anterior contact is developed with the premaxillae. Likely contacts with the palatines are

154 obscured by matrix. The maxillae otherwise form the labial margins of the jaw, the anteroventral

155 margins of the orbit, and the lateral margin of the broad external nares.

156 Pterygoid.- Only the most lateral and medial tips of the left pterygoid are visible (Fig. 2A).

157 Medially, the pterygoid forms the anterior margin of the foramen nervi trigemini and contacts the 158 parietal dorsally. Laterally, the pterygoid forms the processus trochlearis pterygoidei, of which 159 only the damaged lateral tip is free from matrix (Fig. 2C). The process is perpendicular to the 160 midline and almost vertical in lateral view. 
Prootic.- Only the left prootic can be observed in dorsal view and its sutures are obscured by

162 localized damage to the surface of the skull. The left prootic clearly contacts the descending

163 process of the parietal anteromedially and the quadrate laterally. Contacts are certainly present

164 with the supraoccipital posteromedially and the opisthotic posteriorly, but their orientation and

165 size cannot be estimated with confidence. The left prootic partially roofs the foramen nervi

166 trigemini and together with the left quadrate forms the foramen stapedio-temporale, which is

167 situated at the anterior margin of the otic capsule and oriented anteriorly (Fig. 2A).

168 Opisthotic.- Only the external aspects of the opisthotics can be observed. Within the upper

169 temporal fossa, the opisthotics contact the supraoccipital anteromedially, the quadrate

170 anterolaterally, the squamosal posterolaterally, and the exoccipital posteromedially.

171 Quadrate.-Much of the quadrates remain on both sides of the skull, but most surfaces are

172 damaged, making it difficult to discern its original shapes and contacts. At the very least, the

173 quadrate contacts the quadratojugal anterodorsally and the squamosal posteriorly along the skull

174 surface. Within the upper temporal fossa, the quadrate contacts the squamosal posteriorly, the

175 opisthotic posteromedially, and the prootic anteromedially. Although damage to the middle ear is

176 significant, it is apparent that the quadrates fully enclosed the incisura columella auris and

177 Eustachian tube and that the quadrates fully formed the highly reduced antrum postoticum.

178 However, matrix obscures the presence of a possible precolumellar fossa. In lateral view (Fig.

$1792 \mathrm{C})$, the mandibular condyle of the quadrate projects ventrally, beyond the ventral outline of the 180 cavum tympani.

181 Supraoccipital.-The supraoccipital is heavily eroded and some of its contacts are obscured

182 by damage. It is therefore not possible to assess its possible contribution to the dorsal skull roof

183 or the length of the supraoccipital crest. Within the upper temporal fossa, the supraoccipital 
184 certainly contacts the parietal anteromedially, the prootic anterolaterally, the opisthotic

185 posterolaterally, and the exoccipital posteriorly. In posterior view, the supraoccipital roofs the

186 foramen magnum and contacts the exoccipitals ventrally.

187 Exoccipital. - The exoccipitals are both present, but their ventral portions are obscured by

188 matrix. These bones form the lateral margins of the foramen magnum, contact the supraoccipital 189 dorsally, the opisthotic anterolaterally, but their likely ventral contacts with the basioccipital are 190 obscured. Although the occipital condyle is heavily damaged, the sulcus left by the contact

191 between the exoccipitals laterally and the basioccipital ventrally are still visible (Fig. 2E). 192

MATERIAL \& METHODS

194 We integrated the holotype of Piramys auffenbergi into the phylogenetic matrix of Ferreira et al. 195 (2018) to assess its relationships to other pleurodires. Obtaining CT scans of this specimen would have been desirable, as this would help clarify the morphology of the palate, but was not 197 feasible within the context of this study due to logistic hurdles. The matrix was modified through the addition of a new character (ch. 245: PM, median notch on upper jaw; see Supplementary

199 Files) and by updating the scorings of some taxa based on new observations by one the authors 200 (GSF) (see Supplementary Files for full list of changes). As in the original analysis (Ferreira et al., 2018), twelve characters $(14,18,19,71,95,96,99,101,119,129,174,175)$ were interpreted as forming morphoclines and were ordered in the analysis. The resulting matrix was analyzed in TNT v. 1.5 (Goloboff \& Catalano, 2016) using a traditional search with 2000 replicates of Wagner trees, random seed set to 0, branch-swapping algorithm Tree Bisection Reconnection $(\mathrm{TBR})$, hold $=0$, and collapsing zero-length branches according to rule ' 1 '. The most parsimonious trees (MPTs) were subject to a second round of TBR and a strict consensus was 
207 obtained from the resulting MPTs. Consistency (CI) and Retention (RI) indexes, Bremer support, 208 and resampling values (bootstrap and jackknife, using 1000 resamples for calculating absolute 209 and difference of frequencies; Goloboff et al., 2003) were retrieved using implemented functions 210 in TNT.

\section{RESULTS}

213 The search yielded 270 MPTs with 1134 steps $(\mathrm{CI}=0.288 ; \mathrm{RI}=0.748)$. The strict consensus (see

214 Supplementary Files) differs slightly from the results of Ferreira et al. (2018) by yielding a 215 polytomy in the clade that includes the extant Erymnochelys madagascariensis (Grandidier 1867) and Peltocephalus dumerilianus (Schweigger 1812). Piramys auffenbergi is retrieved with relatively high support (Bremer support $=2$; see Supplementary Files) inside Stereogenyini, in a polytomy with Stereogenys cromeri Andrews, 1901 and Shweboemys pilgrimi (Fig. 3).

\section{DISCUSSION}

221

222

223

224

225

226

227

228

229

\section{Alpha taxonomy and phylogenetic relationships}

Prasad (1974) documented in the original description and figures of the holotype of Piramys auffenbergi the presence of large nasals, elongate prefrontals, small frontals that do not contribute to the orbits, and deep upper temporal emarginations. Prasad (1974) unfortunately did not explain why he felt Piramys auffenbergi to be an emydine, but we note that the presence of nasals is neither consistent with an assignment to Emydinae in particular, nor Testudinoidea more generally, as testudinoids universally lack nasal bones (Gaffney, 1979). Our re-examination of the type specimen allows us to better evaluate the cranial morphology and taxonomic affinities of this taxon and to present a more detailed list of diagnostic characters. 
The most apparent differences in our interpretation of the skull is that nasals are absent, that

231

232

233

234

235

236

237

238

239

240

241

242

243

244

245

246

247

248

249

250

251

the prefrontals are situated at the front of the orbits, that the frontals broadly contribute to the

orbits, that the margin of the upper temporal emargination is not preserved, and that a trochlear

process is present on the pterygoid. The presence of a trochlear process of the pterygoid

combined with the absence of nasals clearly hint at pelomedusoid affinities for Piramys

auffenbergi (Gaffney, 1979; Gaffney, Tong \& Meylan, 2006; Joyce, 2007). The trochlear process

is almost completely embedded in matrix, but its lateral tip can be seen anterior to the otic

capsule (Fig. 2C).

The posteriorly broadened skull, small anterior opening of the antrum postoticum, and a mandibular condyle projecting ventrally from the cavum tympani in lateral view (Fig. 2C) suggest stereogenyine affinities (Gaffney et al., 2011; Ferreira et al., 2015). The results of our phylogenetic analysis (Fig. 3) support this initial hypothesis, even though Piramys auffenbergi is scored as "unknown" for several characters that support the monophyly of Stereogenyini. The majority of characters that resolve relationships within Stereogenyini, e.g., presence of a secondary palate with a midline cleft (Gaffney et al., 2011; Ferreira et al., 2015), refer to features in the ventral region of the skull. Unfortunately, this region is covered by matrix in GSI 18133, hampering a more detailed account of its taxonomic affinities. Nevertheless, the pinched snout (ch. 41, state 1), premaxillae protruding anteriorly beyond the dorsal edge of the apertura narium externa (ch. 43, state 1), the small opening of the antrum postoticum (ch. 86, state 2), the ventral projection of the mandibular condyle (ch. 90, state 1), and the median notch in the upper jaw (ch. 246, state 2) supports Piramys auffenbergi as a Stereogenyini with close affinities to Stereogenys cromeri and Shweboemys pilgrimi (Fig. 3). 
252

253

254

255

256

257

258

259

260

261

262

263

264

265

266

267

268

269

270

271

272

273

274

Comparisons of Piramys auffenbergi with other Asian stereogenyines reveal osteological and chronological distinctness. The Bugti Hills in Pakistan, the type locality of Brontochelys gaffneyi, are now considered to be late Oligocene in age (Welcome et al., 2001; see discussion in the next section) whereas the Irrawaddy Beds in Myanmar, the type locality of Shweboemys pilgrimi, are thought to be Pliocene/Pleistocene age (Thein, $\mathrm{Nu} \&$ Pyone, 2012). The sediments exposed on Piram Island are dated as late Miocene (Nanda, Sehgal \& Chauhan, 2017) and Piramys auffenbergi therefore is temporally distinct. Piramys auffenbergi differs from Brontochelys gaffneyi by the presence of a pinched snout, anterodorsally facing orbits, and a median notch in the upper jaw. On the other hand, Piramys auffenbergi differs from Shweboemys pilgrimi by the presence of an interorbital space that is narrower than the diameter of the orbits and the straight prefrontal-frontal suture. Furthermore, Piramys auffenbergi can be distinguished from both other Asian stereogenyines by the presence of a narrow interorbital groove, the more posterodorsally located foramen nervi trigemini, and the anterior, instead of dorsal, opening of the foramen stapedio-temporale. We are therefore able to confirm the validity of Piramys auffenbergi, though not as a testudinoid cryptodire, but rather as a podocnemidid pleurodire.

\section{Paleoecology and biogeography}

Members of Stereogenyini are currently thought to be durophagous, because they have broad and flat triturating surfaces combined with a secondary palate (Ferreira et al., 2015), features that are prevalent among extant turtles with durophagous dietary preferences (Foth, Rabi \& Joyce, 2017). The palate is not exposed in the holotype of Piramys auffenbergi and we are therefore not able to assess the diet of this taxon with confidence. However, the high maxillae, anterodorsally oriented orbits, and posteriorly broadened skull with space for well-developed adductor muscles (Fig. 3) 
275 are features consistent with this life style. Considering the placement of Piramys auffenbergi

276 within Stereogenyini we therefore predict the presence of durophagous features in this taxon as

277 well.

278 Members of Stereogenyini are furthermore thought to have had a marine, or at least coastal,

279 lifestyle based on limb morphology (Weems \& Knight, 2013), shell morphology (Pérez-García, 280 2017), and depositional environments (Ferreira et al., 2015). Although most stereogenyine taxa

281 have indeed been recovered from sediments that represent coastal or open sea depositional

282 environments (Ferreira et al., 2015), we here note that all known Asian stereogenyines were

283 collected from continental deposits, at least as indicated by the prevalence of terrestrial mammals

284 in combination with fresh water aquatic fish and reptiles. In particular, the type of Brontochelys

285 gaffneyi was collected from late Oligocene (not Miocene as reported Wood, 1970; Gaffney et al.,

286 2011) continental sediments exposed in the region of Dera Bugti, Pakistan (Marivaux et al.,

287 1999; Welcome et al., 2001), Shweboemys pilgrimi from the continental Plio/Pleistocene

288 Irrawaddy Beds of Myanmar (Thein, Nu \& Pyone, 2012), and, as demonstrated herein, Piramys

289 auffenbergi from the continental late Miocene middle Siwaliks of India (Nanda, Sehgal \&

290 Chauhan, 2017). However, the more marine adapted African representatives of the Tethyan clade

291 Stereogenyita, in particular Stereogenys cromeri and Lemurchelys diasphax, indicate a certain

292 amount of ecological fluidity within the group. Bothremydids, another clade of pelomedusoid

293 pleurodires, also present a combination of marine and continental forms (e.g., Rabi, Tong \&

294 Botfalvai, 2012), suggesting that a high tolerance to saline waters may be a more widespread

295 feature among side-necked turtles. This is also hinted at by experimental analyses (Bower et al.,

296 2016). However, as deltaic and marine sediments often interfinger finely and as estuarine and

297 coastal turtles are expected to be found in numerous coastal facies, we suggest that the available 
298 data is not sufficient to establish a rigorous pattern for the moment. Nevertheless, the fact that

299 our phylogenetic analysis retrieves two geographically separated clades, the Tethyan

300 Stereogenyita and the South American Bairdemydita, suggests that the even more salt tolerant

301 forms were not highly marine, as greater amounts of dispersal and less endemism were otherwise 302 to be expected.

303 Despite the broad geographic distribution of stereogenyines across North and South America, 304 Africa, and India, they did not achieve the degree of cosmopolitanism seen in modern sea turtles 305 (Chelonioidea; TTWG 2017). Instead, it appears that they were restricted to equatorial and 306 subtropical regions of the northern hemisphere (Fig. 4). This hints at the possibility that their 307 distribution was limited by cooler temperatures outside of the tropics.

CONCLUSIONS

310 Our re-examination of the type specimen revealed the presence of pelomedusoid features in 311 Piramys auffenbergi, e.g., presence of a pterygoid trochlear process in combination with the 312 absence of nasals. Another set of characters suggested a Stereogenyini affinity which was 313 confirmed by the results of our phylogenetic analysis of a global matrix for Pleurodira. Piramys 314 auffenbergi is nested closer to the other Asian stereogenyines Brontochelys gaffneyi and 315 Shweboemys pilgrimi. The phylogenetic position and provenance of Piramys auffenbergi is in 316 accordance with the Stereogenyini broad geographic distribution and proposed high dispersal 317 capability, but the relations within this lineage, with a South American and an African/Asian 318 clade, suggest they were not as cosmopolitan as modern sea turtles. 
321 We would like to thank all officials and supporting staff at the Curatorial Division of the

322 Geological Survey of India and of the Indian Museum for generously providing access to

323 collections under their care, in particular Senior Geologist A. Bhattacharya, Senior Geologist M.

324 R. Moulick, and Senior Geologist A. K. Mondal. The editor, Virginia Abdala, and the reviewers,

325 Juliana Sterli, Márton Rabi and Torsten Scheyer, are thanked for insightful comments that helped

326 improve the quality of the manuscript.

327

REFERENCES

329

330

331

332

333

334

335

336

337

338

339

340

341

342

Andrews CW. 1901. Preliminary note on some recently discovered extinct vertebrates from Egypt (Part II). Geological Magazine 8:436-444.

Andrews CW. 1903. On some pleurodiran chelonians from the Eocene of the Fayum, Egypt. Annals and Magazine of Natural History Series 7:115-122.

Bower DS, Scheltinga DM, Clulow S, Clulow J, Franklin CE, Georges A. 2016. Salinity tolerances of two Australian freshwater turtles, Chelodina expansa and Emydura macquarii (Testudinata: Chelidae). Conservation Physiology 4:cow042.

Broin F. 1988. Les tortues et le Gondwana. Examen des rapports entre le fractionnement du Gondwana et la dispersion géographique des tortues pleurodires à partir du Crétacé. Studia Palaeocheloniologica 2:103-142.

Cope ED. 1865. Third contribution to the herpetology of tropical America. Proceedings of the Academy of Natural Sciences of Philadelphia 1865:185-198.

Cope ED. 1868. On the origin of genera. Proceedings of the Academy of Natural Sciences of Philadelphia 1868:242-300. 
343 Dacqué E. 1912. Die fossilen Schildkröten Aegyptens. Geologische und Palaeontologische

$344 \quad$ Abhandlungen 14:275-337.

345 Ferreira GS, Bronzati M, Langer MC, Sterli J. 2018. Phylogeny, biogeography and

346 diversification patterns of side-necked turtles (Testudines: Pleurodira). Royal Society Open

347 Science 5:171773 DOI 10.1098/rsos.171773.

348 Ferreira GS, Rincón AD, Solórzano A, Langer MC. 2015. The last marine pelomedusoids

349 (Testudines: Pleurodira): a new species of Bairdemys and the paleoecology of Stereogenyina.

$350 \quad$ PeerJ 3:e1063 DOI 10.7717/peerj.1063.

351 Foth C, Rabi M, Joyce WG. 2017. Skull shape variation in recent and fossil Testudinata and its relation to habitat and feeding ecology. Acta Zoologica 98:310-325 DOI 10.1111/azo.12181.

Gaffney ES. 1979. Comparative cranial morphology of recent and fossil turtles. Bulletin of the American Museum of Natural History 164:65-376.

Gaffney ES, Meylan PA, Wood RC, Simons E, Campos DA. 2011. Evolution of the sidenecked turtles: the Family Podocnemididae. Bulletin of the American Museum of Natural History 350:1-237 DOI 10.1206/350.1.

Gaffney ES, Scheyer TM, Johnson KG, Bocquentin J, Aguilera OA. 2008. Two new species of the side necked turtle genus, Bairdemys (Pleurodira, Podocnemididae), from the Miocene of Venezuela. Paläontologische Zeitschrift 82:209-229 DOI 10.1007/BF02988411.

Gaffney ES, Tong H, Meylan PA. 2006. Evolution of the side-necked turtles: the families Bothremydidae, Euraxemydidae, and Araripemydidae. Bulletin of the American Museum of Natural History 300:1-700 DOI 10.1206/0003-0090(2006)300[1:EOTSTT]2.0.CO;2. 
364 Gaffney ES, Wood RC. 2002. Bairdemys, a new side-necked turtle (Pelomedusoides:

365 Podocnemididae) from the Miocene of the Caribbean. American Museum Novitates 3359:136628 DOI 10.1206/0003-0082(2002)359<0001:BANSNT>2.0.CO;2.

367 Goloboff PA, Catalano SA. 2016. TNT version 1.5, including a full implementation of 368 phylogenetic morphometrics. Cladistics 32:221-238 DOI 10.1111/cla.12160.

369 Goloboff PA, Farris JS, Källersjö M, Oxelman B, Ramírez MJ, Szumik CA. 2003.

370 Improvements to resampling measures of group support. Cladistics 19:324-332 DOI

$371 \quad$ 10.1111/j.1096-0031.2003.tb00376.x

372 Grandidier A. 1867. Liste des reptiles nouveaux decouverts, en 1866, sur la côte sud-ouest de Madagascar. Revue et Magasin de Zoologie Pure et Appliquée 19:232-234.

Joyce WG. 2007. Phylogenetic relationships of Mesozoic turtles. Bulletin of the Peabody Museum of Natural History 48:3-102.

Marivaux L, Vianey-Liaud M, Welcomme J-L. 1999. Première découverte de Cricetidae (Rodentia, Mammalia) Oligocènes dans le synclinal Sud de Gandoï (Bugti Hills, Balouchistan, Pakistan). Comptes Rendus de l'Académie des Sciences 329:839-844.

Nanda AC, Sehgal RK, Chauhan PR. 2017. Siwalik-age faunas from the Himalayan Foreland Basin of South Asia. Journal of Asian Earth Sciences 162:54-68 DOI 10.1016/j.jseaes.2017.10.035.

Pérez-García A. 2017. New information and establishment of a new genus for the Egyptian Biology 1-11 DOI 10.1080/08912963.2017.1374383. 
387

388

389

390

391

392

393

394

395

396

397

398

399

400

401

402

403

404

405

406

407

408

409

Rabi M, Tong H, Botfalvai G. 2012. A new species of the side-necked turtle Foxemys (Pelomedusoides: Bothremydidae) from the Late Cretaceous of Hungary and the historical biogeography of the Bothremydini. Geological Magazine 149:662-674.

Schweigger AF. 1812. Prodromus Monographiae Cheloniorum. Konigsberger Archiv für Naturwissenschaft und Mathematik 1:406-458.

Swinton WE. 1939. A new fresh-water tortoise from Burma. Records of the Geological Survey of India 74:548-551.

Thein ZMM, Nu TT, Pyone WW. 2012. Lithofacies and depositional environment of the Irrawaddy Formation in Myogintha Area, Pauk Township, Magway region. Universities Research Journal 5:69-82.

TTWG [Turtle Taxonomy Working Group]. 2017. Turtles of the world: annotated checklist and atlas of taxonomy, synonymy, distribution, and conservation status (8th ed). Chelonian Research Monographs 7:1-292.

Weems RE, Knight JL. 2013. A new species of Bairdemys (Pelomedusoides: Podocnemididae) from the Oligocene (Early Chattian) Chandler Bridge Formation of South Carolina, USA, and its paleobiogeographic implications for the genus. In: Brinkman D, Holroyd P, Gardner J, eds. Morphology and evolution of turtles, Vertebrate paleobiology and paleoanthropology series. Netherlands: Dordrecht, 289-303.

\section{Welcome J-L, Benammi M, Crochet J-Y, Marivaux L, Métais G, Antoine P-O, Baloch I.} 2001. Himalayan forelands: paleontological evidence for Oligocene detrital deposits in the Bugti Hills (Balochistan, Pakistan). Geological Magazine 138:397-405.

Wood RC. 1970. A review of the fossil Pelomedusidae (Testudines, Pleurodira) of Asia. Breviora 357:1-24. 
410 Wood RC, Díaz de Gamero ML. 1971. Podocnemis venezuelensis, a new fossil pelomedusid

411 (Testudines, Pleurodira) from the Pliocene of Venezuela and a review of the history of

$412 \quad$ Podocnemis in South America. Breviora 376:1-23.

413

414

Figure 1: The type locality of Piramys auffenbergi.

415

(A) A simplified map of India. Gujarat State is highlighted in purple, all other states in various

416

shades of grey. (B) Detailed view of the Gulf of Khambhat. Piram Island is highlighted in purple.

417

418

Figure 2: GSI 18133, Piramys auffenbergi, holotype, late Miocene of Piram Island, Gujarat,

India.

420

Photographs and illustrations of specimen in (A) dorsal, (B) right lateral, (C) left lateral, (D)

421

anterior, and (E) posterior views. Abbreviations: $\mathrm{cm}$, condylus mandibularis; et, Eustachian tube;

422

$f n t$, foramen nervi trigemini; $f r$, frontal; $f s t$, foramen stapedio-temporale; ju, jugal; $m x$, maxilla;

423

$o c$, occipital condyle; $o p$, opisthotic; $p a$, parietal; $p f$, prefrontal; $p o$, postorbital; $p r$, prootic; $p t p$,

424

processus trochlearis pterygoidei; $q j$, quadratojugal; $q u$, quadrate; so, supraoccipital; $s q$,

425 squamosal.

426

427

Figure 3: Phylogenetic hypothesis of Stereogenyina.

428

A time-calibrated cladogram depicting a portion of the strict consensus topology of 270 MPTs

429 with 1134 steps retrieved from the phylogenetic analysis using ordered characters. Dark lines highlight the known temporal distribution of a taxon and the colored continent symbols highlight their known spatial distribution. The full tree is provided in the Supplementary File S2.

432 


\section{Figure 4: Geographic distribution of stereogenyines.}

434 Section of world map indicating localities of extinct taxa assigned to Stereogenyini. Red circles 435 indicate Stereogenyita, green circles Bairdemydita, and blue circles non-Stereogenyita and non436 Bairdemydita steregeonyines. 1, Bairdemys venezuelensis; 2, B. thalassica Ferreira et al., 2015; 437 3, B. sanchezi; 4, B. winklerae Gaffney et al., 2008; 5, B. hartsteini Gaffney \& Wood, 2002; 6, 438 "B." healeyorum Weems \& Knight, 2013; 7, Mogharemys blanckenhorni (Dacqué, 1912); 8, 439 Cordichelys antiqua; 9, Latentemys plowdeni; 10, Stereogenys cromeri; 11, Lemurchelys 440 diasphax Gaffney et al., 2011; 12, Brontochelys gaffneyi; 13, Shweboemys pilgrimi; 14, Piramys 441 auffenbergi. Abbreviations: EG, Egypt, MM, Myanmar, PK, Pakistan, PR, Puerto Rico, US, 442 United States of America, VE, Venezuela. 
Figure 1

The type locality of Piramys auffenbergi.

(A) A simplified map of India. Gujarat State is highlighted in purple, all other states in various shades of grey. (B) Detailed view of the Gulf of Khambhat. Piram Island is highlighted in purple.

Bhavnagar

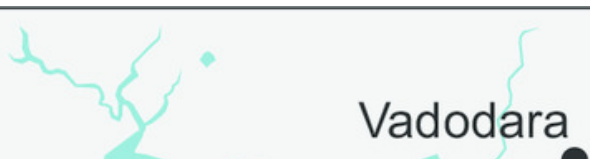

Piram Island

B
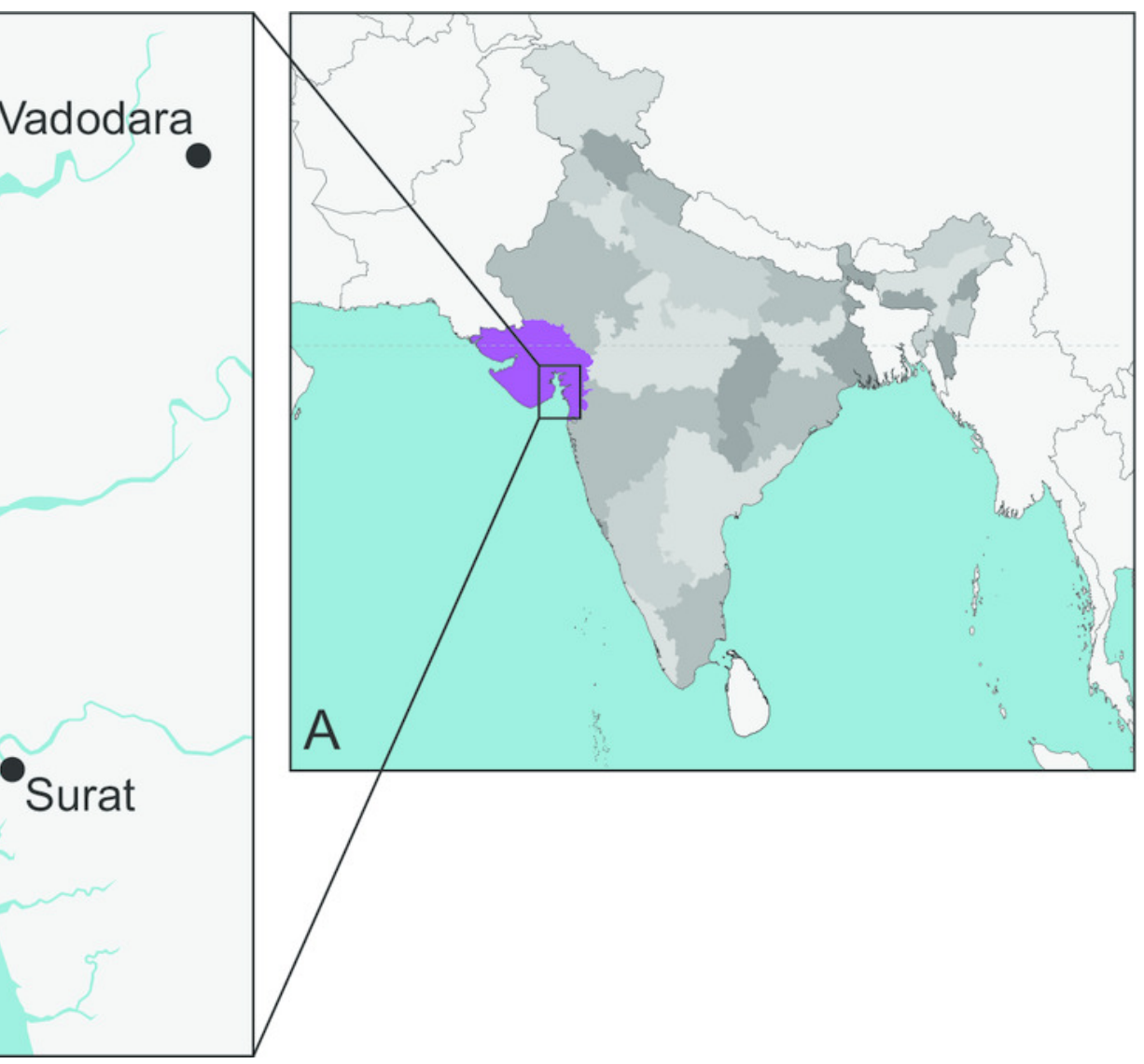


\section{Figure 2}

GSI 18133, Piramys auffenbergi, holotype, late Miocene of Piram Island, Gujarat, India.

Photographs and illustrations of specimen in (A) dorsal, (B) right lateral, (C) left lateral, (D) anterior, and (E) posterior views. Abbreviations: $\mathrm{cm}$, condylus mandibularis; et, Eustachian tube; fnt, foramen nervi trigemini; fr, frontal; fst, foramen stapedio-temporale; ju, jugal; $m x$, maxilla; oc, occipital condyle; op, opisthotic; pa, parietal; $p f$, prefrontal; po, postorbital; $p r$, prootic; ptp, processus trochlearis pterygoidei; qj, quadratojugal; qu, quadrate; so, supraoccipital; sq, squamosal. 


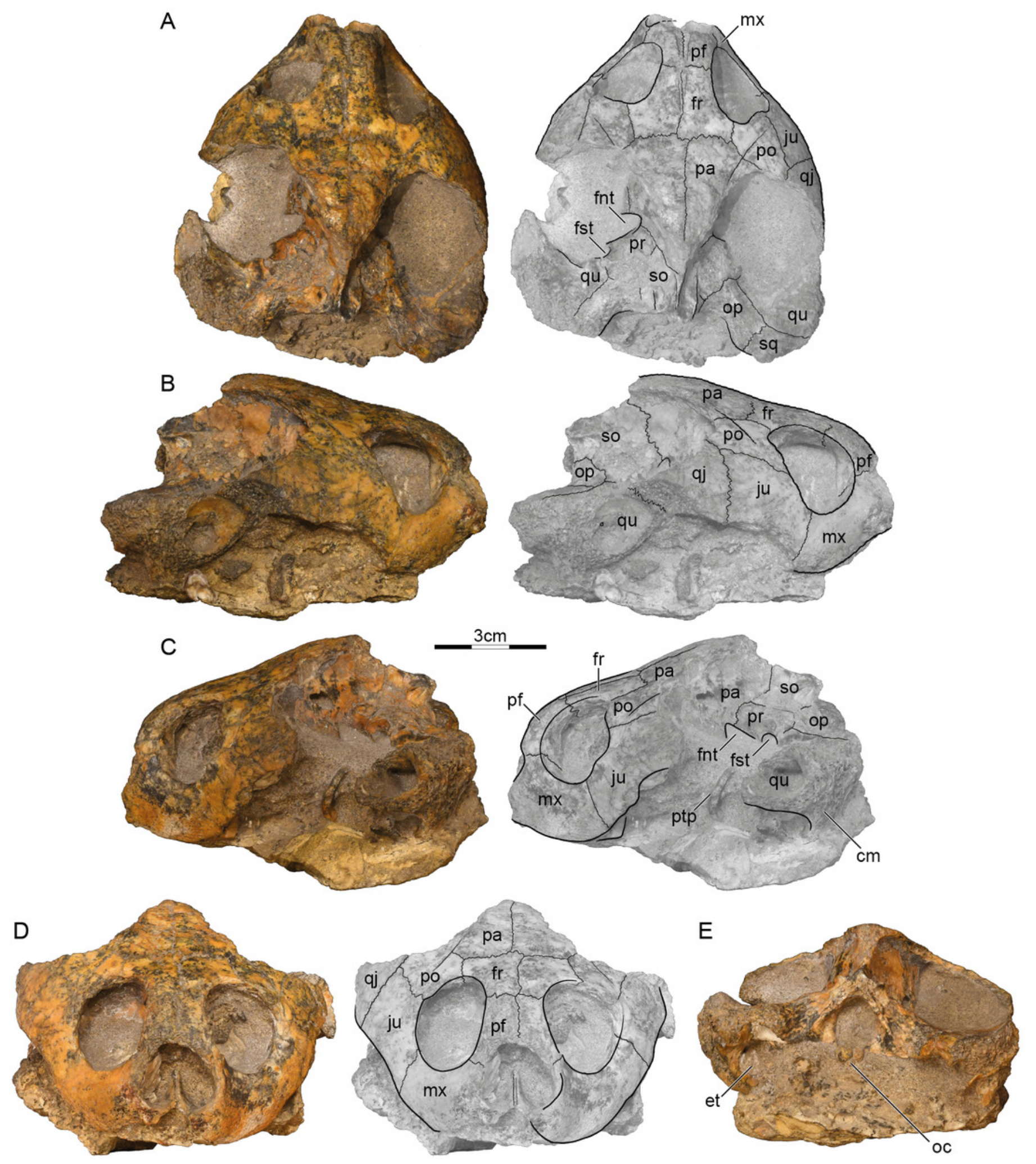


Figure 3

Phylogenetic hypothesis of Stereogenyina.

A time-calibrated cladogram depicting a portion of the strict consensus topology of 270 MPTs with 1134 steps retrieved from the phylogenetic analysis using ordered characters. Dark lines highlight the known temporal distribution of a taxon and the colored continent symbols highlight their known spatial distribution. The full tree is provided in the Supplementary File S2.

\begin{tabular}{|l|l|}
\hline Pleistocene & \\
\cline { 2 - 2 } Pliocene & Piacenzian \\
\cline { 2 - 2 } & Zanclean \\
\hline \multirow{4}{*}{ Miocene } & Messinian \\
\cline { 2 - 2 } & Tortonian \\
\cline { 2 - 2 } & Serravallian \\
\cline { 2 - 2 } & Langhian \\
\cline { 2 - 2 } & Burdigalian \\
\cline { 2 - 2 } & Aquitanian \\
\hline \multirow{2}{*}{ Oligocene } & Chattian \\
\cline { 2 - 2 } & \\
\hline & Rupelian \\
& \\
\hline
\end{tabular}

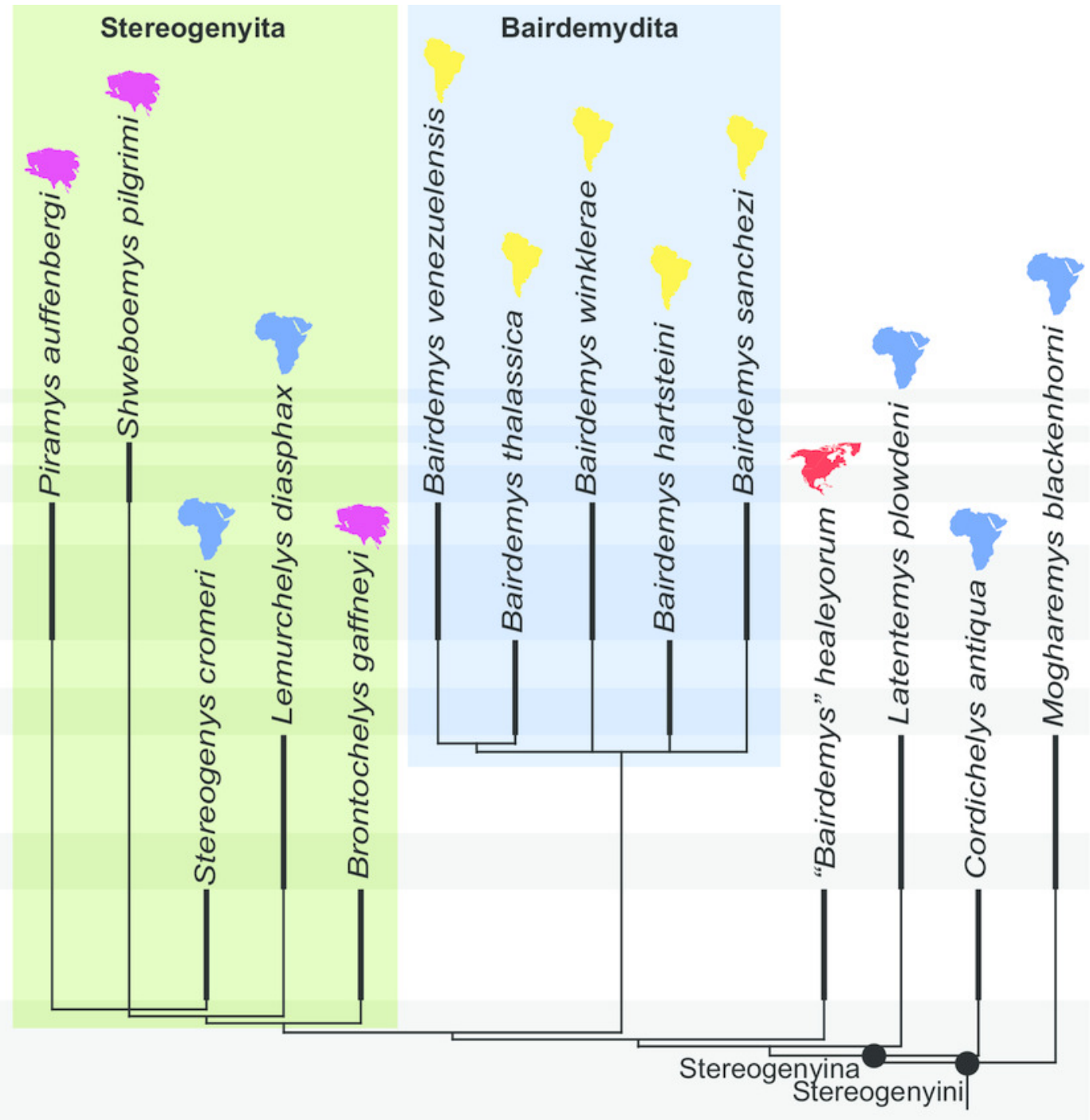




\section{Figure 4}

Geographic distribution of stereogenyines.

Section of world map indicating localities of extinct taxa assigned to Stereogenyini. Red circles indicate Stereogenyita, green circles Bairdemydita, and blue circles non-Stereogenyita and non-Bairdemydita steregeonyines. 1, Bairdemys venezuelensis; 2, B. thalassica Ferreira et al., 2015; 3, B. sanchezi; 4, B. winklerae Gaffney et al., 2008; 5, B. hartsteini Gaffney \& Wood, 2002; 6, "B." healeyorum Weems \& Knight, 2013; 7, Mogharemys blanckenhorni (Dacqué, 1912); 8, Cordichelys antiqua; 9, Latentemys plowdeni; 10, Stereogenys cromeri; 11, Lemurchelys diasphax Gaffney et al., 2011; 12, Brontochelys gaffneyi; 13, Shweboemys pilgrimi; 14, Piramys auffenbergi. Abbreviations: EG, Egypt, MM, Myanmar, PK, Pakistan, PR, Puerto Rico, US, United States of America, VE, Venezuela.

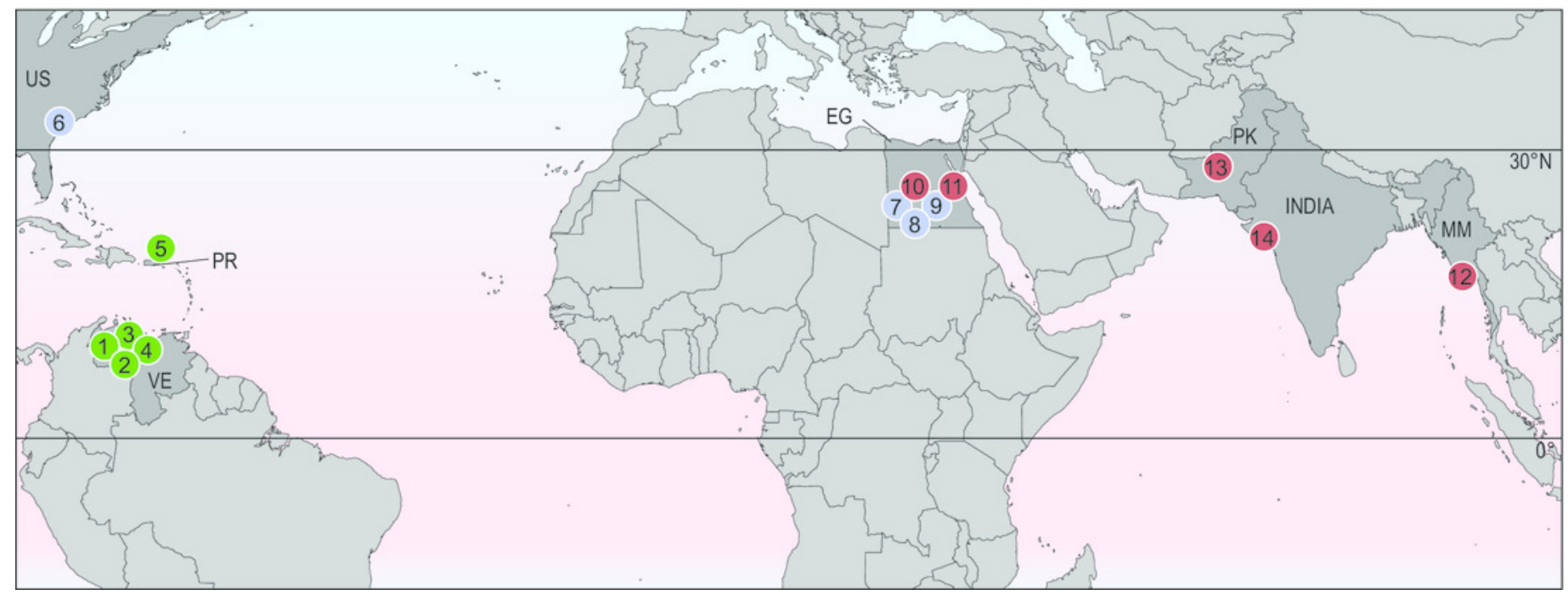

